\title{
To Log or Not to Log? SWOT Analysis of Self- Tracking
}

\author{
Na $\mathrm{Li}^{1}$ and Frank Hopfgartner ${ }^{2}$ \\ ${ }^{1}$ Dublin City University, na.li3@mail.dcu.ie \\ ${ }^{2}$ University of Glasgow, frank.hopfgartner@glasgow.ac.uk
}

\begin{abstract}
With more and more wearable devices and smartphone apps being released that are capable of unobtrusively recording various aspects of our life, we are currently witnessing the emergence of a new trend. Followers of this trend rely on these apps and devices to track their every day activities and to gain insights into their personal well-being. Although promoted by various players on the market, the use of such techniques does not come without risks or drawbacks. In this chapter, we use the SWOT matrix, which is commonly used by business strategists to evaluate the strengths, weaknesses, opportunities, and threats of selftracking activities.
\end{abstract}

\section{Introduction}

Our body is constantly emitting signals that, if listened to carefully, allow us to better understand the state of our personal well-being. For example, feeling weak and tired after a long sleep can be seen as indication of poor sleep quality. ${ }^{1}$ It might reveal evidence regarding our personal fitness level or our mental state. Being aware of the importance of our body's signals, medical doctors heavily rely on them when they have to make a diagnosis. Adopting these methods, a growing number of people have started to constantly measure the performance level of their bodies, using a variety of equipment to collect and store the data. These individuals can be considered as part of the Quantified Self (QS) movement that uses instruments to record numerical data on all aspects of our lives: input (food consumed, surrounding air-quality), states (mood, arousal, blood oxygen levels), and performance (mental, physical). Such self-monitoring and self-sensing, which combines wearable sensors and wearable computing, is also sometimes referred to as Lifelogging, although lifelogging describes the process of recording and storing any type of personal data rather than just user-centric sensor data.

\footnotetext{
${ }^{1}$ See also the chapter of Fischer about sleeplogging in this volume
} 
The technology research and advisory company Gartner predicts that by 2017 , the QS movement will have evolved into a new trend with around $80 \%$ of consumers collecting or tracking personal data and creating lifelogs. Moreover, they predict that by 2020 , the analysis of consumer data collected from wearable devices will be the foundation for up to five percent of sales from the Global 1000 companies $^{2}$. Given these predictions, it comes as no surprise that more and more companies are trying to enter the market with novel wearable devices. In fact, a multitude of devices, services and apps are now available that track almost everything we do nowadays.

Although there are certainly some situations when such information can be useful, the creation of lifelogs is not without risk. In 2011, the European Union agency ENISA $^{3}$ evaluated the risks, threats and vulnerabilities of lifelogging applications with respect to central topics such as privacy and trust issues. In their final report, they highlight that lifelogging itself is still in its infancy but nevertheless will play an important role in the near future (Ioannis et al., 2011). Therefore, they recommend further research in order to influence its evolution to "be better prepared to mitigate the risks and [to] maximize the benefits of these technologies." Following up on this study, in this paper we focus on the benefits and pitfalls that derive from the use of self-tracking activities. As common in business strategy analytics, we will concentrate on the strengths, weaknesses, opportunities, and threats (SWOT) that should shed further light on the use of selftracking devices.

This paper is organized as follow: in Section 2 we give a brief introduction to Lifelogging and QS. Section 3 details a SWOT analysis on self-tracking.

Discussions and conclusions are given in Section 4.

\section{Background}

The activity of recording personal bio signals and metrics using software and tools is referred to as self-tracking. Different reasons can be found that motivate people to start recording and analyzing personal data. A large share of self-trackers include people with chronic medical conditions who rely on technology to track their personal well-being. Other self-trackers are motivated to observe and to increase their personal fitness and wellness levels. At the same time, an increasing amount of users track their own activities for their own infotainment. A prominent movement that promotes self-tracking is the so-called Quantified Self movement.

Quantified Self

\footnotetext{
${ }^{2} \mathrm{http}: / /$ www.enterpriseefficiency.com/mobile/author.asp?section id $=1129 \&$ doc_id $=269098$

${ }^{3} \mathrm{http}: / /$ www.enisa.europa.eu
} 
Quantified Self (QS) has received increasing attention from academia (e.g. Rapp et al. 2014; Li et al. 2014) and industry. Swan (Swan, Emerging PatientDriven Health Care Models: An Examination of Health Social Networks, Consumer Personalized Medicine and Quantified Self-Tracking, 2009) defines self tracking as the action of regular, voluntary elicitation and collection of all types of metrics that can be related to an individual. This includes health-related data like body weight, sleep quantity and quality, blood results, blood pressure, nutrition habits and $\operatorname{mood}^{4}$, but also other information such as location, work time or weather and finances. The gathered data is often visualized in diagrams, graphs or by tag clouds. Apart from health-related information, QS also includes keeping record of social interactions, emails, networks, and social media status updates, or activities such as viewing television, using the computer, general use of time, driving habits, work productivity, monitoring environmental conditions, or other activities that can be analyzed to achieve personal goals.

Regarding the motivation to start QS, Wolf explained in a 2010 TED talk (Wolf, The Quantified Self (TED Talk)., 2010) that their main interest was on seeing how people incorporate technologies into their lives and what changes in society this adaptation causes. Fascinated by the significant increase of technologies that allow us to keep records of our daily activities, they started organizing meetings to discuss the personal and social impact of the development of the smartphone and other technologies that could serve as mobile sensing platforms. In 2012, "some 19\% of smartphone owners have at least one health app on their phone. Exercise, diet, and weight apps are the most popular types" (Fox and Duggan 2012). A more recent study revealed that as much as 70\% of adults in the USA keep track of at least one health indicator" (Fox and Duggan 2013).

Nowadays, QS focuses on two dimensions of the impact of self-tracking. First of all, it concentrates on gathering personal information by quantifying and analyzing personal data. This is expressed with the slogan "self-knowledge through numbers", the main motto of the movement. Secondly, the movement promotes the idea of sharing track records of certain aspects of one's life with a worldwide audience. Here, their blog serves as the central hub of this community, but it also includes many other channels such as real-life meet up groups, regional and global conferences (Labs). As of December 2014, over 500 tools and apps are listed on this website, indicating the high popularity and diversity of the movement. On top of that, large numbers of wearable devices have been introduced to the market. A recent report by ABI Research ${ }^{5}$ suggests that by 2018, the number of wearable computing devices will have reached 480 million units.

While QS mainly focuses on gathering bio-metrics to track personal well-being, gathering additional personal information is referred to as lifelogging.

\section{Lifelogging}

\footnotetext{
${ }^{4}$ See also the chapter of Pritz about mood tracking in this volume.

${ }^{5} \mathrm{https}: / /$ www.abiresearch.com/press/wearable-computing-devices-like-apples-iwatch-will
} 
Lifelogging is the process of automatically and unobtrusively recording one's life and storing it in digital format, hence granting the lifelogger easy access to this record. Lifelogs can consist of heterogeneous sensor data such as images, GPS, $\mathrm{WiFi}$, accelerometers, light level, etc. The lifelogging vision is that the lifelogger never forgets anything since everything they do is being tracked, photographed and recorded. Consequently, lifeloggers can have direct access to the most important moments of their lives if they used tools to record it.

One of the early adopters of lifelogging techniques is Gordon Bell of Microsoft. Within the "MyLifeBits" project (Bell and Gemmell 2010), they captured all of their personal data in digital form and created software that allowed them to access this data. ${ }^{6}$ The goal of this technology was to create a personal archive, or a "portable, infallible, artificial memory" that can be exploited to increase job productivity, serve as a basis for medical treatment, improving performances in school and many other scenarios.

Another lifelogging pioneer is Steve Mann, who uses wearable computing to create a record of his life. He performed significant studies on visual memory prosthetics that transformed his eye into a camera and his body into a Web server. He refers to this technique as 'cyborg logging' or 'glogging' ${ }^{7}$.Wearable cameras play an important role in research on lifelogging since analyzing camera data streams can reveal a lot of information. One wearable lifelogging device, the SenseCam (Hodges, et al., 2006), automatically captures images every 30 seconds, resulting in thousands of recorded images per day. It is a camera with a fish-eye lens, about the size of a cigarette packet. The camera is usually worn around the neck and can be set to take photographs when triggered by such things as changes in the light, ambient heat or body temperature. The SenseCam has since been improved with new models and competing devices available for purchase.

The SenseCam has received a lot of attention from scientific researchers who focused in 100+ papers on various aspects of lifelogging. Examples are critically assessed in the next section where we evaluate self-tracking by performing a SWOT analysis. For a detailed description of state-of-the-art lifelogging techniques, see Gurrin et al. (Gurrin et al. 2014). An essay about the potential effect of lifelogging on our society is provided by Selke (Selke, 2014).

\section{SWOT Analysis}

Although the idea of self-tracking is not new, the quality and quantity of quantifying activities is currently gaining momentum. This is mainly due to the increased perception of self-tracking as being a key factor for individual personal achievements and success, but of course also due to the increasing availability of software and tools to support self-tracking. Given the personal nature of the data that is recorded by these tools, issues arising from the existence of such data should be carefully considered by every self-tracker. Most of all, this includes

${ }^{6}$ See also Jim Gemmell's article on Thing-Logging and the contribution to MyLifeBits in this volume.

${ }^{7} \mathrm{http}: / /$ wearcam.org/glogs.htm 
implications for privacy and security, but also for other aspects that can have a strong impact on the self-tracker, on society and on the economy.

In business environments, a common technique to assess the challenges arising from new situations is to perform a SWOT analysis. SWOT is an acronym for Strengths, Weaknesses, Opportunities, and Threats. Assuming that our aim is to achieve a specific goal, strengths can be seen as a resource, a unique approach, or capacity that assist us in reaching this specific goal. Weaknesses are limitations, faults, or defects that hinder progress toward this goal. Opportunities pertain to internal or external input factors such as trends that increase demand for what can be provided when achieving the goal. Threats refer to unfavorable situations that can serve as a barrier or constraint for achieving the goal. SWOT analyses are commonly performed to better understand specific aspects and to support decision-making by looking at a situation from different perspectives and from different entities involved. A SWOT analysis provides a framework to review strategies, the position and direction of a company or business endeavor, or any other aspects that can be important for a company. Strengths and Weaknesses are often considered to be internal factors, while Opportunities and Threats generally relate to external factors. For this reason, a SWOT analysis is sometimes called Internal-External Analysis and the SWOT Matrix is sometimes called an IE Matrix.

Generally, a SWOT analysis serves to uncover the optimal match between the internal strengths and weaknesses of a given entity and the environmental trends (opportunities and threats) that the entity must face on the market. In this section we perform a SWOT analysis to evaluate self-tracking activities.

\subsection{Strengths ${ }^{8}$}

In a SWOT analysis, the strengths should indicate what is to be gained from adopting a new technique or direction. In our case, we analyze some benefits that a user of self tracking techniques can expect, including raising self-awareness, total recall, leaving digital heritage, and creating collective memories.

\section{Raising Self-Awareness}

Swan (Swan, The quantified self: fundamental disruption in big data science and biological discovery, 2013) argues that the heterogeneous tracking sensor streams which can be recorded and stored in a personal archive can be exploited to analyze users' lifestyle. An automated analysis of all input streams could, for example, reveal that the self-tracker has poor sleep quality due to external factors such as a noisy environment, stress factors, an unhealthy sleeping position or other factors that could be captured by sensors.

\footnotetext{
${ }^{8}$ See also Heyen's article on the new production of knowledge by self-tracking in this volume.
} 
An obvious domain that can benefit from self-tracking is the monitoring of one's food consumption. Unhealthy nutrition is one of the main reasons for diseases of affluence and, consequently, there is a great need to raise people's awareness on their eating habits. Self-tracking can be helpful for keeping an eye on diseases, health indicators, and the effectiveness of care. Various studies (see Tsai and Wadden (2005) for an overview) have shown that people who keep track of what they eat on paper, in an App, or in some other form, have better success at losing weight, managing their diet, controlling their portions, and sticking to healthy habits. Food tracking apps (e.g. Kitamura et al. 2009) in particular raise users' awareness on the quantity of food that they consume on a daily basis. This constant awareness can lead to a change in personal eating habits, leading to improved personal well-being. Personal success stories, e.g. promoted by the Weight Watchers company provide further evidence that the ability to record and also share food intake plays an important role in personal well-being. ${ }^{9}$

Furthermore, various studies (e.g. Warburton et al. 2006) report a direct connection between physical activities and personal well-being. Regular physical activity is a resource for body and soul (Services, 2006). On the one hand, an active lifestyle can contribute to reducing the risk of cardiovascular diseases, obesity and complaints of the muscular and skeletal system (Blair, Kohl, Paffenbarqer, Clark, Cooper, \& Gibbons, 1989). On the other hand, regular physical exercise can reinforce the mental well-being. The World Health Organization (WHO) describes lack of exercise as the fourth important risk factor for mortality (Organization, 2010). For adults they recommend a moderateintensity activity for 2.5 hours per week. Various studies suggest that personal achievement is one of the main driving forces behind sports activities. Nicholls (Nicholls, 1989) argues, for example, that one of the main reasons for the success of competitive sports such as running, tennis, or swimming is the possibility to directly compare one's physical abilities with others. Another motivation is to experience (and to extend) physical limitations. This can in particular be observed in extreme sports such as base diving, or other dangerous activities. Within this context he refers to task-oriented and ego-oriented sports. In both cases, individual achievement, either by outperforming others or by reaching new limits, is the main reason to perform sports. Hence, in order to motivate people to get more physically active, personal aims need to be identified and targeted. Members of QS rely on the power of numbers to measure personal achievements. By recording their physical activities using step counters, accelerometers, or other wearable sensors, people can directly measure how far they are from reaching their personal goals (e.g., Swan 2009).

In a work scenario, services such as RescueTime ${ }^{10}$ allow tracking the amount of time spent on applications and websites. By showing how often web browser, email client, chat clients or other applications are used, this particular service helps to better understand how efficiently users work in front of a computer.

\footnotetext{
${ }^{9}$ See also Schmechel's article on calorie tracking and the history of the Weight Watchers in this volume.

${ }^{10} \mathrm{https}: / /$ www.rescuetime.com/
} 
RescueTime advertises their service as a means to "find your ideal work-life balance". They suggest that increasing self-awareness can lead to a change in behavior that will consequently lead to a more efficient use of time.

\section{Total recall}

One of the key selling points of lifelogging technology is that everything that lifeloggers experience will be recorded and stored in memory. Memory is the process by which information is encoded, stored, and retrieved. Given enough stimuli and rehearsal, humans can remember information for many years and recall that information whenever required. However, not every stimulus is strong enough to help trigger every specific memory. Therefore, using external memory to help people to compensate for memory deficits has been considered to be one of the most effective methods to counteract the effects of age-related memory loss (e.g., Arcega et al. 2013). Studies have shown that lifelogging can successfully be applied to create such external memory aids. Lifelogging tools create comprehensive digital archives that can act as an extension of human memory. The most important input for such lifelogs are visual information that show personal activities through the medium of images or video. For example, visual lifelogs consisting of pictures have been shown to help people with Alzheimer's decease; there are many applications for dementia and aging memory loss are many (e.g. Hodges et al. 2006).

Apart from supporting users with memory deficits, visual lifelogs can also capture life moments that are worth remembering. ${ }^{11}$ Cathal Gurrin, who has been an active lifelogger for many years, revealed in a keynote speech (Gurrin, Keynote: Experience of a Lifelogger: Tasks and Challenges., 2013) given at the Second International Workshop on Lifelong-User Modelling that his lifelog contains a picture of the first time, he met his then soon-to-be girlfriend. What initially was a trivial moment in his life turned out to be a significant event for his life. Obviously, capturing such "trivial" moment on camera would have been a great coincidence without the use of a lifelogging camera.

\section{Leaving a Digital Heritage}

Assuming that lifelogs are created over a lifetime and are also constantly backed up to avoid loss of data, chances are high that these lifelogs will survive their own creators, thus leaving a detailed view of the lifelogger's life experience. A similar situation can be observed on social networking sites such as Facebook or GooglePlus where the user profiles of deceased users remain online. Therefore, one strength of lifelogging technologies is the ability to leave detailed evidence of the very own existence behind. A detailed investigation into this topic is provided by Burneleit (Burneleit, 2011), who argues for the creation of a digital shrine, or "digital space" that is left behind as digital heritage.

\footnotetext{
${ }^{11}$ See also Berg's et al.'s article and developers' presumptions about relevance in life in this volume.
} 
Picking up on this issue, the following scenario has been addressed by Bluepatch Productions and Floating World Productions in their play Oh look, hummingbirds, which premiered at the 2012 Dublin Fringe Festival. In this play, a journalist is given the opportunity to view the memories of a loved-one who has passed away. This service is provided by a futuristic company that specializes on keeping one's lifelogging legacy and enabling selected people to access this data. Although this remains fiction from today's point of view, a few companies ${ }^{12}$ have started working on creating such lifelogs and preparing them as digital heritage. This indicates that leaving digital heritage can also be seen as an opportunity that arises from the use of lifelogging technologies. In summary, self-tracking technologies provide tools for those who fear being forgotten after death.

\section{Collective Memory}

Since ancient times, libraries such as the famous Alexandria have been used to keep material that is of some cultural, scientific or other value. Libraries and librarians have tools to appraise material, assessing it, indexing it, and preserving it for long-term access so that it can be found later. Besides preserving material, digital libraries maintain and disseminate an accurate and compelling record of the heritage of our past cultures from ancient cave paintings, to verbal storytelling, written manuscripts, the printing press and audio and video recordings in the recent past. Nowadays, our digital libraries make preserved documents related to the heritage of past cultures more accessible, but thus far we have still mostly preserved essentially the same materials as we did before, and we are not preserving our present culture. By aggregating and analyzing individuals' lifelogs, we can even go one step further and create a kind of collective memory of a group of people or citizens. We argue that by aggregating lifelogs into community views, these lifelogs can represent a comprehensive archive of our cultural heritage. In other words, lifelogs can create a collective memory of life in the 21st century. Collective memories are memories fed from multiple individuals. Examples are the collective knowledge created through collaboration in digital social networks or the collective memory of a city built on the individual memories of its citizens.

\subsection{Weaknesses}

Weaknesses in a SWOT analysis should indicate the main risks that should be considered when adapting a new policy or direction. From the point of view of a self tracker, this includes misinterpretation, privacy issues and security leaks. The weaknesses are outlined in the remainder of this section.

\section{Misinterpretation}

With the growing importance of the Internet, one could also witness the growth of online health-oriented information platforms such as PubMed ${ }^{13}$ and Scopus ${ }^{14}$,

\footnotetext{
${ }^{12}$ See for example http://eterni.me/.

${ }^{13} \mathrm{http}: / / w w w . n c b i . n l m . n i h . g o v /$ pubmed/
} 
which enable researchers and professionals to check up on the latest research results on biomedical topics (Falagas, Pitsouni, Malietzis, \& Pappas, 2008). While these databases provide detailed access to state-of-the-art research results, they are less suitable for the general public who would like to check up on symptoms that they are experiencing. According to Morahan-Martin, up to 4.5\% of all Internet searches are about health-related topics (Morahan-Martin, 2004), indicating the significance of this topic in our life. A negative side effect that appeared with the rise of such information platforms is "cyberchondria", i.e. people becoming anxious about their health based on the data they collect (White and Horvitz 2008). With the increasing amount of devices and apps available that suggest detailed insights into personal well-being, people might be tempted to overinterpret this data. This is particularly challenging since the accuracy of this data remains unclear. Therefore, the self-tracker is always advised to question the data they are receiving. Wolf (Wolf, The Data-Driven Life, 2010) considers this to be a serious issue since health self-trackers often try to find their own way to improve symptoms without any professional guidance. Relying on such data can be dangerous if done without professional training and an amount of skepticism.

\section{Privacy and Security}

According to Rainie et al. (Rainie et al. 2013), approximately $86 \%$ of adult Internet users in the US have taken steps to protect their online privacy, such as setting up encrypted communication or using anonymity services (proxies, VPNs, Tor network, or using aliases instead of their real names). This indicates that there is a general awareness of the risks to their privacy through Internet use. In the context of self-tracking, privacy concerns are very important since this data can reveal significantly more personal information than the average interaction on the Web (e.g., Hopfgartner and Jose 2010). Health apps for smartphones and tablets, for example, support saving and transferring sensitive information on user's blood sugar and blood pressure in the cloud. Given the sensitivity of this data, high demand for privacy and security protection are required with apps and gadgets that track a person (Rawassizadeh and Tjoa 2010; Brake 2014). Assuming that in the not-too-far future, everything we do will be tracked and traced (e.g. in a Smart Home, or Smart City environment where a multitude of sensor streams come together), an analysis of this big data can reveal a lot of personal information (Nafus and Sherman 2014), with serious implications for the users' security and privacy.

Lifelogging systems usually consist of different components that are responsible for collecting, storing, analyzing and presenting data (e.g. Albatal et al. 2013). Each component must be able to protect the lifelogger's privacy and security by making sure that the data cannot be accessed by third parties. As common in software systems, the more components that exist, the higher the effort to guarantee such privacy (McHugh, 2001). Each additional component (e.g.,

${ }^{14}$ http://www.scopus.com/ 
additional sensors or platforms that are included in the lifelogging process) in the system increases the risk of attack as each component introduces new potential weaknesses that could be targeted by attackers.

In current systems, one of the main components that can be targeted by attackers is the data transmission component (Wu, Chen, Wu, \& Cardei, 2007). For example, most wearable sports activity tracking devices that are on the market contain sensors to detect motion, but are not designed to track locations. In order to provide a location-tracking functionality, data created by these devices needs to be synchronized with another device or the cloud for further analysis. Many manufacturers rely on Bluetooth Low Energy technology to wirelessly synchronize data (e.g., Omre and Keeping 2010). By capturing this wireless transmission, the lifelogger can be tracked by a potential attacker (Solon, Callaghan, Harkin, \& McGinnity, 2006).

While some lifelogging devices store their data locally, most lifelogging services (e.g. Albatal et al. 2013) require users to upload and share the data that is recorded by their apps on central servers, also often referred to as the cloud. Although cloud computing providers are focusing on securing their services, keeping data on external hard disks can be risky and should be carefully considered. Especially since this data does often not only consist of the raw data that is recorded by the lifelogging device (e.g. accelerometer data captured from a step counting device), but also of additional personal data that users had to provide in order to take full advantage of the service provided. Users could be required, for example, to provide their age, relationship status, or other sensitive details which are used as mandatory input parameters in the services' algorithms.

One important privacy aspect is the ability to switch off the trackers and devices, hence leaving no record of the current situation. Self-trackers need to have the ability to switch off everything if they feel that it would be inappropriate or if someone might object to what is being recorded. On the other hand, switching off a device is also information that, if analyzed, could reveal information about the user. Devices such as the SenseCam come with the feature to temporarily deactivate the device, e.g. to avoid taking pictures when the lifelogger is in the rest room. Recently, researchers developed a technique called PlaceAvoider for owners of first person cameras to 'blacklist' sensitive spaces (like bathrooms and bedrooms). This technique provides a way to identify and prevent the sharing of sensitive images (Templeman, Korayem, Crandall, \& Kapadia, 2014).

\subsection{Opportunities}

In a SWOT analysis, opportunities and threats are identified by analyzing external origins. In the case of self-tracking, this means that the society and the companies who produce the self-trackers (or who receive the data) are the focus. In the remainder of this section, we outline various opportunities that arise for these groups, namely business success, adaptive services for the community and research progress. 


\section{Business}

The main motivation for commercial companies to produce tracking devices is to increase their profit margins. For companies, three main sources of revenue can be identified.

First of all, companies can make a financial profit by selling the hardware devices to their customers. Given that major companies such as Google, Motorola, Apple and Microsoft are making significant investments, it is not premature to assume that there is great potentials on the market. Indeed, a recent study by Berg Insight ${ }^{15}$ shows that sales of smart glasses, smart watches and wearable fitness trackers reached 8.3 million units worldwide in 2012, up from 3.1 million devices in the previous year. Estimating an annual growth rate of 50.6 percent, they estimate that 64 million units will be sold in 2017. With the health and fitness sectors potentially taking the lead, wearables will begin to occupy a growing role in the mobile-health sector, and data analytics and big data will become important services linked to their growth. At the same time, with an increasing number of companies entering the market, we see a variety of rather cheap hardware available for purchase. This indicates that selling hardware can not be considered the main source of revenue.

The second main source of income comes from customer subscriptions, i.e. the hardware is sold relatively cheap, but in order to take full advantage of the selftracking service, users have to sign up for an additional service. This could include additional data storage, additional means of visualizing the data (e.g. charts) or other features that bind the customer to the company. An example is the subscription model that the company Narrative ${ }^{16}$ offers to users of their main product, a tiny wearable camera advertised as the Narrative Clip. When buying their relatively cheap device, users currently have to opt for either a three-month, or a 12-month subscription model which allows them to store their photos in the cloud.

Finally, an important source of revenue can come from selling the customers' data for marketing purposes. The analysis of self-tracking data can reveal detailed information about peoples' habits, needs and interests and can therefore be seen as a gold mine for marketers. For example, details about people's running behavior, their age, sex, height, and address can be highly valuable for shoe manufacturers such as Nike as it allows them to initiate very specific targeted market campaigns based on these insights (McClusky, The nike experiment: How the shoe giant unleased the power of personal metrics, 2009).

\section{Adaptive Services}

While the driving force behind the industrial age was to optimize the industrial process using mechanical tools, today we aim to optimize processes by analyzing data that is created by digital devices. Key techniques for a data-centric optimization of processes are personalization, data mining, machine learning,

\footnotetext{
${ }^{15} \mathrm{http}: / /$ www.berginsight.com/ReportPDF/ProductSheet/bi-ce3-ps.pdf

${ }^{16} \mathrm{http}: / /$ getnarrative.com/
} 
knowledge discovery and information management approaches. In other words, context-aware algorithms are required to understand, interpret and react upon input data, and adapt their output based on external input parameters. The English physicist Stephen Hawking even argues that the ability to adapt to change is an indicator of intelligence. In line with this argument, algorithms that adapt to change can be seen as computationally intelligent - or smart. Therefore, we refer to systems that rely on such computational intelligence as smart information systems (Hopfgartner, Smart Information Systems: Computational Intelligence for Real-Life Applications, 2015). As early as 2008, Marissa Mayer, the current CEO of Yahoo! and former vice president of Search Products and User Experience of Google Inc., predicted in an interview held at the LeWeb conference in Paris that "in the future personalized search will be one of the traits of leading search engines". This statement reflects the increasing attention that smart information systems draw from both academia and industry. With increasing computational power, smart algorithms enable us to identify patterns, test research hypotheses or create data models, hence shedding light on the potential usage of this data.

Lifelogs are large repositories that provide a multitude of contextual information. Context is key for the provision of user-centric smart information systems (e.g., Karatzoglou et al. 2010) since it allows understanding the user, and, if comparable data is available, the identification of similar users or items. If the heterogeneous data streams that are capturing aspects of a person's life could be collected into a single stream, that person may be able to benefit from relationships between the different aspects. For example, if you were to regularly listen to The London Philharmonic Orchestra on your portable music player and your mobile telephone sent a GPS location notification to your lifelog, then it would be possible to receive a notification that The Dresden Philharmonic Orchestra was scheduled to perform while you were in Dresden for a meeting. This would not automatically be possible where the different data streams of digital data are separated. An example of middleware architecture for context awareness in lifelogs is presented by Song et al. (Song, Lee, Chung, Rim, \& Lee, 2014).

\section{Advances in Research}

To date, research on health aspects largely relies on traditional data sources which have been recorded under controlled conditions, e.g. within clinical trials. Given the high financial burden that such trials implicate for the researchers, there is hope that personal health data which is voluntarily provided by self-trackers can be exploited to promote further research in the health domain (Swan, The Realization of Personalized Medicine through Crowdsourcing the Quantified Self, and the Participatory Biocitizen, 2012). Data collected passively via self-tracking applications could, for example, be used to support users' responses they provided in field trials. So for example, if users have to provide information on how many physical activities they performed within a specific time period, their response often recalled from memory and thus not always very accurate - could be confirmed (or corrected) using self-tracking data. Besides, by asking for active 
data collection within a trial, less questionnaires might be needed and hence, the burden of remembering their activities can be lifted from the study participants.

Moreover, self-tracking data from a community of users (e.g. Swan 2012), also referred to as the crowd, can be exploited to better understand the living conditions of specific user groups. For example, an aggregated and averaged view of the data recorded using Jawbone devices revealed ${ }^{17}$ that citizens of Tokyo (on average) sleep one hour less than citizens of Melbourne, or that citizens in Stockholm take more steps than people in São Paulo. Concluding from this example, it is evident that a thorough data analysis of self-tracking data can help us to better understand society in general.

\subsection{Threats}

The final aspect of a SWOT analysis focuses on the threats that derive from the use of self-tracking techniques. Again, the focus here lies on the threat considering external parties. In this case, we focus on threats for companies that provide selftracking hardware or services and threats for society in general. In the remainder of this section, we outline the main threats, namely the impact on society and threats for businesses which invest in self-tracking.

\section{Impact on Society}

Among individuals, there is growing interest in, as well as a willingness and opportunity to share personal data with others. People use online groups such as Patients-LikeMe or Crohnology to share medical data with others with similar medical conditions, hoping to learn more about their personal health conditions (Wicks, et al., 2010). How the data will be used, who will have access to the data and when, which regulations and legal protections are in place, and the level of compensation or benefit (both personal and public) is still a big issue. Various parties might have an interest in gaining access to this content-rich data.

First of all, service providers such as health insurance companies might have a strong interest in exploiting this data, e.g. by providing cheaper insurance policies to those customers who can prove that they are physically active or have a healthy diet and life-style. In fact, Olson (Olson, 2014) reports that health insurance companies are becoming increasingly aware of the potential that wearable technology offers. While this might be an actual motivation for users to actually improve their lifestyle, it might result in a financial disadvantage to those who are not willing to get more active or who are not willing to share their data, e.g. because they consider it a breach of their privacy.

Moreover, there is a big threat that the data might be exploited for the creation of detailed user profiles that can eventually be used against the self-tracker. The revelations of Edward Snowden about the National Security Agency (NSA) surveillance on a global scale (Lyon, 2014) showed that, nowadays, systems are capable of processing vast amount of personal data in a way that allows for the

\footnotetext{
${ }^{17}$ https://jawbone.com/blog/jawbone-up-data-by-city/
} 
creation of detailed user profiles. While such surveillance is often advertised as a necessity to protect society from terrorist attacks, it is also considered to be a major threat to human dignity (Baum, 2013). The sensitivity of privacy concerns is also reflected by the perception of self-tracking devices that capture users in proximity to the self-tracker. Caprani et al. (2013) interviewed a visual lifelogger on his experience while wearing a SenseCam for seven years. He argued that although people are curious about the recording device, he did not experience any negative effect on his personal life. Early adopter Steve Mann was a little less fortunate, as he got assaulted in a restaurant in Paris for wearing a camera (Biggs, 2012). When Google released the first version of their optical head-mounted displays (i.e. the Google Glass), similar incidents were reported, eventually leading to the ban of the device in some restaurants and bars (Levy, 2014), name calling and the development of counter-measures that prevent the device from connecting to WIFI access points (Oliver). These cases illustrate that the use of camera devices is often seen as a breach of peoples' privacy.

A big threat is also posed by hackers who intend to use this data for their personal benefit. Friedland and Sommer (Friedland and Sommer 2010), for example, present an algorithm that can be used to identify potential burglary targets based on the geo-location of videos and pictures that have been shared online by the potential victims. They refer to this as cybercasing, i.e. the method of "using online tools to check out details, make inferences from related data, and speculate about a location in the real world for questionable purposes." Considering that many lifelogs contain GPS data, a leakage of this data can be a serious threat for the lifelogger since it may reveal a lot of personal information which may be used against them.

\section{Business}

Various business analysts predict that in the near future, the number of selftrackers will increase significantly and, consequently, many ventures intend to join the market with novel products and services. Although this development can be seen as a big opportunity, the presence of different players on the market also challenges the companies' prospects of success. Competitive markets often result in lower profit margins. Therefore, companies whose initial investment costs are very high face the threat of their investment not being covered by the actual return. At the same time, reducing investment costs, e.g. by using cheaper hardware, or by using fewer resources to develop algorithms or services might backfire and result in an even smaller return of investment. Keeping this in mind, companies are well advised to constantly observe the market and to adjust their product or target group accordingly. An example is the development of Google Glass which was initially developed for a general audience. A constant monitoring of the market eventually convinced Google that this particular product might be more feasible for business customers rather than individuals. Consequently, they stopped selling the product in early 2015 and are now shifting their business to this market. 
Another concern for companies should be the provision of accurate measurement, interpretation and visualization of data. Most self-tracking data is somehow related to users' personal activities. Devices are often advertised as means to monitor one's fitness level. Users might be tempted to completely rely on this data, hence ignoring other (natural and obvious) signals that might suggest otherwise. McKnight et al. (Mcknight, Carter, Thatcher, \& Clay, 2011) argue that trust is the key aspect for the acceptance of technologies. Therefore, businesses are well advised to pay particular attention to this matter. For example, think of devices such as blood glucose meters where trust in the sensor readings is essential for the users' well-being.

\section{Discussion and Conclusion}

With an increasing amount of self-tracking devices and services that enter the market every day, we can also observe an increase in cases where users can benefit from self-tracking. The most popular application of self-tracking is in the area of personal well-being. Self-tracking devices are used to monitor personal fitness levels, thus helping users to make sure that they are benefiting from their workouts, eventually offering them the means to improve their quality of life. Despite these advantages, it is important to remember that self-tracking devices are capable of creating very detailed user profiles. By creating lifelogs, the selftracker creates a very accurate and possibly even intimate image of their personal life.

In this chapter, we have analyzed the strengths, weaknesses, opportunities and threats of self-tracking, commonly referred to as a SWOT analysis. While strengths and weaknesses are approached from the standpoint of view of the selftracker, opportunities and threats are analyzed with external parties in mind. We identified the effect of raising self-awareness, total recall, leaving a digital heritage, and creating a collective memory as clear strengths of self-tracking. Over-tracking and erosion of privacy are presented as its weaknesses. The main opportunities of self-tracking for companies and society include business success, the provision of smart adaptive services that simplify our daily lives, and further advances in research. The main threats are a potentially negative impact on society, especially with respect to privacy concerns, as well as threats for business ventures.

To conclude, we argue that there undoubtedly are definitely various advantages (strengths and opportunities) for everyone involved, but also serious disadvantages (weaknesses and threats). Considering that self-tracking is really focused on individual's data, it should be up to every individual to decide whether they are willing to accept the disadvantages in exchange for the numerous advantages, or if they prefer to ignore this emerging trend. The critical review presented in this paper should assist users in their decision making process. 


\section{Bibliography}

Albatal, R., Gurrin, C., Zhou, J., Yang, Y., Carthy, D., \& Li, N. (2013). Senseseer mobile-cloud-based lifelogging framework. Technology and Society (ISTAS), 2013 IEEE International Symposium on, 144-146. doi:10.1109/ISTAS.2013.6613113.

Arcega, L., Font, J., \& Cetina, C. (2013). Towards Memory-Aware Services and Browsing through Lifelogging Sensing. Sensors, 13(11), 15113-15137. doi:10.3390/s131115113.

Baum, G. (2013). Wacht auf, es geht um die Menschenwürde. Datenschutz und Datensicherheit - DuD, 37(9), 583-584. doi:10.1007/s11623-013-0242-7.

Bell, G., \& Gemmell, J. (2010). Your Life, Uploaded: The Digital Way to Better Memory, Health, and Productivity. New York: Plume.

Biggs, J. (2012). Augmented Reality Explorer Steve Mann Assaulted At Parisian McDonald's, http://techcrunch.com/2012/07/16/augmented-reality-explorer-stevemann-assaulted-at-parisian-mcdonalds/. Accessed 6 March 2015.

Blair, S.N., Kohl, H.W., Paffenbarqer, R.S.J., Clark, D.G., Cooper, K.H., \& Gibbons, L.W. (1989). Physical fitness and all-cause mortality. A prospective study of healthy men and women. The Journal of the American Medical Association, 262(17), 2395-2401. doi:10.1001/jama.1989.03430170057028.

Brake, D.R. (2014). Sharing our Lives Online- Risks and Exposure in Social Media. London: Palgrave Macmillan.

Burneleit, E. (2011). Necrologium Vitae. Master Thesis at University of Applied Sciences Potsdam.

Caprani, N., O'Connor, N., \& Gurrin, C. (2013). Experiencing SenseCam: a case study interview exploring seven years living with a wearable camera. Proceedings of the 4th International SenseCam \& Pervasive Imaging Conference (SenseCam '13), 52-59. doi:10.1145/2526667.2526676.

Falagas, M.E., Pitsouni, E.I., Malietzis, G.A., \& Pappas, G. (2008). Comparison of PubMed, Scopus, Web of Science, and Google Scholar: strengths and weaknesses. The FASEB Journal, 22(2), 338-342. doi:10.1096/fj.07-9492LSF.

Fox, S., \& Duggan, M. (2012). Mobile Health 2012. http://www.pewinternet.org/files/oldmedia/Files/Reports/2012/PIP_MobileHealth2012_FINAL.pdf. Accessed 06 March 2015. 
Fox, S., \& Duggan, M. (2013). Part Three: Tracking for Health. http://www.pewinternet.org/2013/11/26/part-three-tracking-for-health/. Accessed 06 March 2015.

Friedland, G., \& Sommer, R. (2010). Cybercasing the Joint: On the Privacy Implications of Geo-Tagging. Proceedings of the 5th USENIX conference on Hot topics in security (HotSec'10), 1-8.

Gurrin, C. (2013). Keynote: Experience of a Lifelogger: Tasks and Challenges. Keynote at the Lifelong User Modelling Workshop 2013.

Gurrin, C., Smeaton, A.F., \& Doherty, A.R. (2014). Lifelogging: Personal Big Data, Foundations and Trends in Information Retrieval, 8(1), 1-125. doi:10.1561/1500000033.

Hodges, S., Williams, L., Berry, E., Izadi, S., Srinivasan, J., Butler, A., Smyth, G., Kapur, N., \& Wood, K. (2006). SenseCam: A Retrospective Memory Aid, Proceedings of the 8th International Conference of Ubiquitous Computing (UbiComp 2006), 177-193. doi:10.1007/11853565_11.

Hopfgartner, F. (2015). Smart Information Systems: Computational Intelligence for Real-Life Applications, Heidelberg: Springer Verlag.

Hopfgartner, F., \& Jose, J.M. (2010). Semantic User Modelling for Personal News Video Retrieval. In: S. Boll, Q. Tian, L. Zhang, Z. Zhang, \& Y.-P. P. Chen (Eds.), Advances in Multimedia Modeling. 16th International Multimedia Modeling Conference, MMM 2010 (pp. 336-346). Heidelberg: Springer Verlag

Ioannis, A., Brown, I., Dickman, P., Friedewald, M., Irion, K., Kosta, E., Langheinrich, M., McCarthy, P., Osimo, D., Papiotis, S., Pasic, A., Petkovic, M., Spiekermann, S., \& Wright, D. (2011). To log or not to log? - Risks and benefits of emerging life-logging applications. European Network and Information Security Agency (ENISA).

Karatzoglou, A., Amatriain, X., \& Baltrunas, L. (2010). Multiverse Recommendation: N-dimensional Tensor Factorization for Context-aware Collaborative Filtering, RecSys '10 Proceedings of the fourth ACM conference on Recommender systems, 79-86. doi:10.1145/1864708.1864727.

Kitamura, K., Yamasaki, T., \& Aizawa, K. (2009). FoodLog: capture, analysis and retrieval of personal food images via web. CEA '09 Proceedings of the ACM multimedia 2009 workshop on Multimedia for cooking and eating activities, 2330. doi:10.1145/1630995.1631001. 
Labs, QS, Quantified Self Blog, viewed March 2014, < HYPERLINK "http://quantifiedself.com/" http://quantifiedself.com/>.

Levy, K. (2014). A San Francisco Bar Banned Google Glass Because It Doesn't Want Patrons Being Secretly Filmed. Business Insider. http://www.businessinsider.com/san-francisco-bar-bans-google-glass-20143? IR=T . Accessed 17 March 2015.

Li, N., Hopfgartner, F., Plumbaum, T., \& Ruskin, H.J. (2014). QSHP'14: Proceedings of the Workshop on Quantified Self for Personal Healthcare, held in conjunction with IEEE BIBM 2014. IEEE.

Lyon, D. (2014). Surveillance, Snowden, and Big Data: Capacities, consequences, critique. Big Data \& Society, 1(2). doi:10.1177/2053951714541861.

McClusky, M. (2009). The Nike Experiement: How the Shoe Giant Unleased the Power of Personal Metrics, Wired Magazine. http://archive.wired.com/medtech/health/magazine/17-

07/lbnp_nike?currentPage=all. Accessed 17 March 2015.

McHugh, J. (2001). Intrusion and intrusion detection. International Journal of Information Security, 1, 14-35. doi:0.1007/s102070100001.

Mcknight, D.H., Carter, M., Thatcher, J.B., \& Clay, P.F. (2011). Trust in a specific technology: An investigation of its components and measures, $A C M$ Transactions on Management Information Systems (TMIS), 2(2) 12:1-12:25. doi:10.1145/1985347.1985353.

Morahan-Martin, J.M. (2004). How internet users find, evaluate, and use online health information: a cross-cultural review. Cyberpsychology, Behavior, and Social Networking, 7(5), 497-510.

Nafus, D., \& Sherman, J. (2014). Big Data, Big Questions| This One Does Not Go Up To 11: The Quantified Self Movement as an Alternative Big Data Practice. International Journal of Communication, 8, 1784-1794.

Nicholls, J.G. (1989). The Competitive Ethos and Democratic Education, Cambridge: Harvard University Press.

Oliver, J. (2014). Find a Google Glass and kick it from the network. http://julianoliver.com/output/log_2014-05-30_20-52. Accessed 17 March 2015.

Olson, P. (2014). Wearable Tech Is Plugging Into Health Insurance, http://www.forbes.com/sites/parmyolson/2014/06/19/wearable-tech-healthinsurance/. Accessed 17 March 2015. 
Omre, A.H., \& Keeping, S. (2010). Bluetooth low energy: Wireless connectivity for medical monitoring. Journal of Diabetes Science and Technology, 4(2), 457463. doi:10.1177/193229681000400227.

World Health Organisation (2010). Global recommendations on physical activity for health. http://whqlibdoc.who.int/publications/2010/9789241599979_eng.pdf. Accessed 17 March 2015.

Rainie, L., Kiesler, S., Kang, R., \& Madden, M. (2013). Anonymity, Privacy, and Security Online. PewResearchCenter. http://www.pewinternet.org/files/oldmedia//Files/Reports/2013/PIP_AnonymityOnline_090513.pdf. Accessed 17 March 2015.

Rapp, A., Hopfgartner, F., Plumbaum, T., Kummerfeld, B., Kay, J., \& Herder, E. (2014). LinkQS'14: Proceedings of the Workshop Linking the Quantified Self. CEUR-WS. http://ceur-ws.org/Vol-1210/\#LQS2014. Accessed 17 March 2015.

Rawassizadeh, R., \& Tjoa, A.M. (2010). Securing Shareable Life-logs. Social Computing (SocialCom), 2010 IEEE Second International Conference on, 11051110. doi:10.1109/SocialCom.2010.164.

Selke, S. (2014). Lifelogging: Wie die digitale Selbstvermessung unsere Gesellschaft verändert. Berlin: Econ.

U.S. Department of Health and Human Services (2006). Physical Activity and health: A report of the surgeon general. Centers for Disease Control and Prevention. http://www.cdc.gov/nccdphp/sgr/pdf/execsumm.pdf. Accessed 17 March 2015.

Solon, A., Callaghan, M., Harkin, J., \& McGinnity, T. (2006). Case Study on the Bluetooth Vulnerabilities in Mobile Devices. International Journal of Computer Science and Network Security, 6(4), 125-129.

Song, C.-W., Lee, D., Chung, K.-Y., Rim, K.-W., \& Lee, J.-H. (2014). Interactive middleware architecture for lifelog based context awareness. Multimedia Tools and Applications, 71(2), 813-826. doi:10.1007/s11042-013-1362-7.

Swan, M. (2009). Emerging Patient-Driven Health Care Models: An Examination of Health Social Networks, Consumer Personalized Medicine and Quantified SelfTracking. International Journal of Environmental Research and Public Health, 6(2), 492-525. doi:10.3390/ijerph6020492. 
Swan, M. (2012). The Realization of Personalized Medicine through Crowdsourcing the Quantified Self, and the Participatory Biocitizen. Journal of Personal Medicine, 2(3), 93-118. doi:10.3390/jpm2030093.

Swan, M. (2013). The quantified self: fundamental disruption in big data science and biological discovery. Big Data, 1(2), 85-99. doi:10.1089/big.2012.0002.

Templeman, R., Korayem, M., Crandall, D., \& Kapadia, A. (2014). PlaceAvoider: Steering First-Person Cameras away from Sensitive Spaces. In NDSS'14: Proceedings of the 21st Annual Network and Distributed System Security Symposium, Internet Society. http://www.internetsociety.org/doc/placeavoidersteering-first-person-cameras-away-sensitive-spaces

Tsai, A.G., \& Wadden, T.A. (2005). Systematic review: an evaluation of major commercial weight loss programs in the United States. Annuals of Internal Medicine, 142(1), 56-66. doi:10.7326/0003-4819-142-1-200501040-00012.

Warburton, D.E.R., Nicol, C.W., \& Bredin, S.S.D. (2006). Health benefits of physical activity: the evidence. Canadian Medical Association Journal, 174(6), vol 174, no. 6, pp. 801-809. doi:10.1503/cmaj.051351.

White, R., \& Horvitz, E. (2008). Cyberchondria: Studies of the Escalation of Medical Concerns in Web Search. Microsoft Research. http://research.microsoft.com/pubs/76529/TR-2008-178.pdf. Accessed 17 March 2015.

Wicks, P., Massagli, M., Frost, J., Brownstein, C., Okun, S., Vaughan, T., Bradley, R., \& Heywood, J. (2010). Sharing Health Data for Better Outcomes on PatientsLikeMe. Journal of Medical Internet Research, 12(2), e19. doi:10.2196/jmir.1549.

Wolf, G. (2010a, May 2). The Data-Driven Life. The New York Times, p. MM38. http://www.nytimes.com/2010/05/02/magazine/02self-measurementt.html?pagewanted=all\&_r=0. Accessed 17 March 2015.

Wolf, G. (2010b). The quantified self. TED talk. http://www.ted.com/talks/gary_wolf_the_quantified_self. Accessed 17 March 2015.

Wu, B., Chen, J., Wu, J., \& Cardei, M. (2007). A survey of attacks and countermeasures in mobile ad hoc networks. In: Y. Xiao, X.S. Shen, D.-Z. Du (2007), Wireless Network Security, Signals and Communication Technology, (pp. 103-135). New York: Springer US. 
